Article

\title{
Entropy Generation in Flow of Highly Concentrated Non-Newtonian Emulsions in Smooth Tubes
}

\section{Rajinder Pal}

Department of Chemical Engineering, University of Waterloo, Waterloo, ON N2L 3G1, Canada; E-Mail: rpal@uwaterloo.ca; Tel.: +1-519-888-4567 (ext. 32985)

External Editor: Kevin H. Knuth

Received: 23 August 2014; in revised form: 21 September 2014 / Accepted: 28 September 2014 / Published: 7 October 2014

\begin{abstract}
Entropy generation in adiabatic flow of highly concentrated non-Newtonian emulsions in smooth tubes of five different diameters $(7.15-26.54 \mathrm{~mm})$ was investigated experimentally. The emulsions were of oil-in-water type with dispersed-phase concentration $(\phi)$ ranging from $59.61-72.21 \%$ vol. The emulsions exhibited shear-thinning behavior in that the viscosity decreased with the increase in shear rate. The shear-stress $(\tau)$ versus shear rate $(\dot{\gamma})$ data of emulsions could be described well by the power-law model: $\tau=K \dot{\gamma}^{n}$. The flow behavior index $n$ was less than 1 and it decreased sharply with the increase in $\phi$ whereas the consistency index $K$ increased rapidly with the increase in $\phi$. For a given emulsion and tube diameter, the entropy generation rate per unit tube length increased linearly with the increase in the generalized Reynolds number $\left(\operatorname{Re}_{-} n\right)$ on a log-log scale. For emulsions with $\phi \leq 65.15 \%$ vol., the entropy generation rate decreased with the increase in tube diameter. A reverse trend in diameter-dependence was observed for the emulsion with $\phi$ of $72.21 \%$ vol. New models are developed for the prediction of entropy generation rate in flow of power-law emulsions in smooth tubes. The experimental data shows good agreement with the proposed models.
\end{abstract}

Keywords: emulsion; non-Newtonian; power law; entropy generation; pipeline flow; exergy destruction

PACS Codes: $5 ; 47 ; 82$ 


\section{Introduction}

According to the Gouy-Stodola theorem, the rate of loss of work or available energy in a process is directly proportional to the total rate of entropy generation within and outside the control volume. The Gouy-Stodola theorem is expressed mathematically as [1]:

$$
\dot{W}_{\text {lost }}=T_{o} \dot{S}_{G, \text { total }}
$$

where $\dot{W}_{\text {lost }}$ is the rate of lost work, $T_{o}$ is the surroundings temperature, and $\dot{S}_{G, \text { total }}$ is the total rate of entropy generation within and outside the control volume. The greater the rate of entropy generation due to internal and external irreversibilities, the greater is the amount of energy that becomes unavailable for work [2-4]. Thus, it is important from a practical point of view to estimate the rate of entropy generation in a process in order to determine the thermodynamic efficiency of the process.

This article is related to entropy generation in flow of highly concentrated non-Newtonian emulsions of oil-in-water type in smooth tubes. The oil-in-water (designated as $\mathrm{O} / \mathrm{W}$ ) emulsions consist of oil droplets dispersed in a continuum of aqueous phase. Such emulsions are very important industrially [5]. For example, a large number of skincare and makeup creams marketed today are in the form of $\mathrm{O} / \mathrm{W}$ emulsions. One important function of these creams is to prevent dryness of skin by replacing lost moisture and by keeping the skin hydrated over a period of time. The $\mathrm{O} / \mathrm{W}$ emulsions are of considerable importance in the food industry as well. Examples of food emulsions (O/W type) are: milk, mayonnaise, coffee whiteners, and salad dressings. The dispersed-phase (oil droplets) concentration of food emulsions could range from low to very high. For example, milk consists of 3-4 volume percent of dispersed-phase whereas mayonnaise consists of more than 65 volume percent dispersed phase (oil droplets). The pipeline transportation of highly viscous crude oils in the form of $\mathrm{O} / \mathrm{W}$ emulsions has also received special attention in recent years [6-8]. The transportation of highly viscous crude oils, such as bitumen and heavy oils, by pipelines is difficult, especially during cold weather. To facilitate the flow of highly viscous crude oils in pipelines, it is necessary to reduce their viscosity. This can be achieved by forming emulsions of $\mathrm{O} / \mathrm{W}$ type with crude oil as the dispersed phase. The concept of crude oil transportation in the form of $\mathrm{O} / \mathrm{W}$ emulsion has already been utilized commercially in a pipeline $21 \mathrm{~km}$ in length and $20 \mathrm{~cm}$ in diameter in California, and in a pipeline $238 \mathrm{~km}$ in length and $51 \mathrm{~cm}$ in diameter in Indonesia [7]. For emulsion pipelining to be economical, it is important to keep the dispersed-phase (oil) concentration of the emulsion as high as possible and, at the same time, maintain the emulsion viscosity at a reasonable level. However, concentrated $\mathrm{O} / \mathrm{W}$ emulsions are known to exhibit non-Newtonian shear-thinning behavior.

In light of the industrial applications of emulsions just mentioned, it is of practical significance to investigate the production of entropy in emulsion flow in pipelines and other process equipment. In the past, a number of research articles have been published on simultaneous flow of oil and water in pipelines [7,9-22]. The published studies deal with topics such as: phase inversion in emulsion flow [9-12], droplet size and droplet size distribution in emulsion flow [13,14], flow patterns in concurrent flow of oil and water in pipelines [15-17], and pressure drop in pipeline flow of emulsions [7,16-22]. However, little or no attention has been given to the second law analysis and entropy generation in emulsion flows despite the practical significance of the problem. 
This work is in continuation of our earlier study on the production of entropy in flow of emulsions in smooth tubes [23]. Our earlier study was restricted to entropy generation in flow of dilute to moderately concentrated water-in-oil (W/O) emulsions. The emulsions were Newtonian in nature. The key objective of the present work is to experimentally investigate the generation of entropy in flow of highly concentrated surfactant-stabilized oil-in-water $(\mathrm{O} / \mathrm{W})$ emulsions in different diameter tubes. These emulsions exhibited non-Newtonian shear-thinning behavior. Models are also developed for the prediction of entropy generation rate in flow of power-law emulsions in smooth tubes.

It should be pointed out that a number of interesting research articles have been published recently on heat transfer and entropy generation in flow of Newtonian and non-Newtonian fluids [24-33]. Several published articles also deal with the fluid mechanics, thermodynamics, and stability of non-Newtonian fluids in different configurations [34-36]. However, the published studies mostly deal with analytical solutions and simulations related to homogeneous fluids. To our knowledge, little or no experimental and theoretical work has been reported on entropy generation in flow of concentrated non-Newtonian emulsions in tubes.

\section{Theoretical Background}

Consider a control volume with multiple inlets and outlets. Let the control volume be in contact with $N$ heat reservoirs at temperatures $T_{i}$ 's and the environment at $T_{o}$. Let the rates of heat transfer from heat reservoirs to the control volume be $\dot{Q}_{i}$ 's and from environment to the control volume be $\dot{Q}_{o}$. Let the temperatures of the control volume boundary portions in contact with the heat reservoirs and the environment be $T_{b i}$ 's and $T_{b o}$, respectively. Entropy balance on the control volume gives:

$$
\sum_{I n} \dot{m} s+\frac{\dot{Q}_{o}}{T_{b o}}+\sum_{N} \frac{\dot{Q}_{i}}{T_{b i}}-\sum_{O u t} \dot{m} s+\dot{S}_{G, C V}=\frac{\partial S_{C V}}{\partial t}
$$

where $\dot{m}$ is the mass flow rate, $s$ is the specific entropy, $\dot{S}_{G}$ is the rate of entropy generation, "In" refers to inlets, "Out" refers to outlets, and subscript " $C V$ " refers to control volume. Doing entropy balance on the surroundings, one can write:

$$
-\frac{\dot{Q}_{o}}{T_{b o}}-\sum_{N} \frac{\dot{Q}_{i}}{T_{b i}}+\dot{S}_{G, \text { surr }}=\frac{\partial S_{\text {surr }}}{\partial t}=-\frac{\dot{Q}_{0}}{T_{0}}-\sum_{N} \frac{\dot{Q}_{i}}{T_{i}}
$$

This equation could be re-cast as:

$$
\dot{S}_{G, \text { surr }}=\frac{\dot{Q}_{0}}{T_{b o}}\left[1-\frac{T_{b o}}{T_{0}}\right]+\sum_{N} \frac{\dot{Q}_{i}}{T_{b i}}\left[1-\frac{T_{b i}}{T_{i}}\right]
$$

Adding the entropy balances for control volume and surroundings, the following result is obtained:

$$
\dot{S}_{G, \text { total }}=\frac{\partial S_{C V}}{\partial t}+\sum_{\text {Out }} \dot{m} s-\frac{\dot{Q}_{o}}{T_{b o}}-\sum_{N} \frac{\dot{Q}_{i}}{T_{b i}}-\sum_{I n} \dot{m} s+\frac{\dot{Q}_{0}}{T_{b o}}\left[1-\frac{T_{b o}}{T_{0}}\right]+\sum_{N} \frac{\dot{Q}_{i}}{T_{b i}}\left[1-\frac{T_{b i}}{T_{i}}\right]
$$

This equation could be re-cast as:

$$
\dot{S}_{G, t o t a l}=\frac{\partial S_{C V}}{\partial t}+\sum_{O u t} \dot{m} s-\frac{\dot{Q}_{o}}{T_{o}}-\sum_{N} \frac{\dot{Q}_{i}}{T_{i}}-\sum_{I n} \dot{m} s
$$


The thermodynamic efficiency $\eta$ of a flow process is defined as the ratio of actual shaft work $\left(\dot{W}_{s h}\right)$ produced to the maximum shaft work $\left(\dot{W}_{\text {sh,ideal }}\right)$ obtainable from a given change in the properties of the flow streams $[2,4]$. Thus:

$$
\eta=\frac{\dot{W}_{\text {sh }}}{\dot{W}_{\text {sh,ideal }}}=\frac{\dot{W}_{\text {sh,ideal }}-\dot{W}_{\text {lost }}}{\dot{W}_{\text {sh,ideal }}}
$$

Using the Gouy-Stodola theorem, the thermodynamic efficiency of a process can be expressed as:

$$
\eta=1-\frac{T_{o} \dot{S}_{G, \text { total }}}{\dot{W}_{\text {sh,ideal }}}
$$

According to the second law of thermodynamics, $\dot{S}_{G, t o t a l}>0$ for any irreversible process and therefore, the efficiency of a process expressed in Equation (8) is always less than one. Only in the limiting case of complete reversibility where the process is completely reversible without any internal and external irreversibilities, $\dot{S}_{G, \text { total }}=0$ and the thermodynamic efficiency of the process is one.

Consider now the steady and adiabatic flow of fluid in a pipe. According to Equation (2):

$$
\dot{S}_{G, C V}=\dot{m}\left(s_{2}-s_{1}\right)=\dot{m} \Delta s
$$

For adiabatic incompressible flow in a horizontal pipe in the absence of any shaft work, the enthalpy change is zero $\left(\Delta h=h_{2}-h_{1}=0\right)$ according to the first law for open systems. Using the following fundamental thermodynamic relation:

$$
d h=T d s+\frac{d P}{\rho}
$$

it follows that:

$$
T \frac{d s}{d x}=\frac{1}{\rho}\left(-\frac{d P}{d x}\right)
$$

where $T$ is temperature, $P$ is pressure, $\rho$ is density, and $d P / d x$ is pressure gradient in the direction of flow. Combining Equations (9) and (11), we obtain:

$$
\dot{S}_{G}^{\prime}=\dot{m} \frac{d s}{d x}=\frac{\dot{m}}{\rho T}\left(-\frac{d P}{d x}\right)
$$

where $\dot{S}_{G}^{\prime}$ is the rate of entropy generation per unit pipe length.

The Fanning friction factor $f$ in pipe flow is defined as:

$$
f=\frac{(-d P / d x)(D / 4)}{\rho \bar{V}^{2} / 2}
$$

where $D$ is the pipe diameter and $\bar{V}$ is the average fluid velocity in pipe. From Equations (12) and (13), it follows that:

$$
\dot{S}_{G}^{\prime}=\frac{\pi}{2 T}\left(f \rho D \bar{V}^{3}\right)
$$


In pipeline flow of non-Newtonian power-law fluids, friction factor is related to the generalized Reynolds number $\mathrm{Re}_{-} n$ defined as:

$$
\operatorname{Re}_{-} n=\frac{\rho D^{n} \bar{V}^{2-n}}{K 8^{n-1}\left[\frac{3 n+1}{4 n}\right]^{n}}
$$

where $K$ and $n$ are the power-law parameters which appear in the following power-law model of the fluid:

$$
\tau=K \dot{\gamma}^{n}
$$

In this power law model, $\tau$ is the shear stress and $\dot{\gamma}$ is the shear rate. The power-law parameter $K$ is often referred to as "consistency index" and $n$ is called "flow behavior index". For Newtonian fluids, $n=1$ and $K=\mu$ ( $\mu$ is the viscosity) and the generalized Reynolds number $\operatorname{Re}_{-} n$ reduces to the conventional Reynolds number. For pseudo-plastic (shear-thinning) fluids, $n<1$ and for dilatant (shearthickening) fluids, $n>1$.

From Equations (14) and (15), it can be readily shown that:

$$
\dot{S}_{G}^{\prime}=\left(\frac{\pi}{2 T}\right)\left[\frac{\left(a_{n}\right)^{3 /(2-n)}}{\rho^{(1+n) /(2-n)} D^{(4 n-2) /(2-n)}}\right](f)\left(\operatorname{Re}_{-} n\right)^{3 /(2-n)}
$$

where $a_{n}$ is given as :

$$
a_{n}=K 8^{n-1}\left[\frac{3 n+1}{4 n}\right]^{n}
$$

When the fluid is Newtonian, $n=1, K=\mu, a_{n}=\mu$, and the expression for entropy generation rate per unit pipe length reduces to :

$$
\dot{S}_{G}^{\prime}=\left(\frac{\pi}{2 T}\right)\left[\frac{\mu^{3}}{\rho^{2} D^{2}}\right]\left(f \operatorname{Re}^{3}\right)
$$

where Re is the conventional Reynolds number defined as: $\operatorname{Re}=\rho D \bar{V} / \mu$. Equation (19) was derived in our previous study [23] on entropy generation in pipeline flow of Newtonian emulsions.

For laminar flow of non-Newtonian power-law fluids in pipes, the friction factor is related to the generalized Reynolds number Re_ $n$ as follows:

$$
f=\frac{16}{\mathrm{Re}_{-} n}
$$

For turbulent flow of non-Newtonian power-law fluids in hydraulically smooth pipes, the friction factor is given by the following Dodge-Metzner equation [37]:

$$
\frac{1}{\sqrt{f}}=\left(\frac{4}{n^{0.75}}\right) \log _{10}\left[f^{(1-0.5 n)} \operatorname{Re} \_n\right]-\frac{0.4}{n^{1.2}}
$$

The Dodge-Metzner equation reduces to the well-known Prandtl-von Karman law in the special case of Newtonian fluids $(n=1, K=\mu)$ :

$$
\frac{1}{\sqrt{f}}=4 \log _{10}[\operatorname{Re} \sqrt{f}]-0.4
$$


The disadvantage of Equation (21) is that it is not explicit in $f$ and has to be solved numerically. Dodge and Metzner [37] also proposed a Blasius-type equation explicit in $f$ for non-Newtonian fluids:

$$
f=\frac{\alpha_{n}}{\left(\operatorname{Re}_{-} n\right)^{\beta_{n}}}
$$

where $\alpha_{n}$ and $\beta_{n}$ are functions of $n$ reported graphically. The plots of $\alpha_{n}$ versus $n$ and $\beta_{n}$ versus $n$ can be described accurately by the following expressions:

$$
\begin{gathered}
\alpha_{n}=0.0077 \ln (n)+0.078 \\
\beta_{n}=0.25(n)^{-0.22}
\end{gathered}
$$

The critical Reynolds number for transition from laminar to turbulent flow in power-law non-Newtonian fluids is given as [38]:

$$
\left(\operatorname{Re}_{-} n\right)_{\text {critical }}=\frac{2100(4 n+2)(5 n+3)}{3(3 n+1)^{2}}
$$

Substitution of the friction factor expressions from Equations (20) and (23) into Equation (17) leads to the following relations for entropy production in pipeline flow of non-Newtonian power-law fluids:

$$
\begin{array}{cc}
\dot{S}_{G}^{\prime}=\left(\frac{8 \pi}{T}\right)\left[\frac{\left(a_{n}\right)^{3 /(2-n)}}{\rho^{(1+n) /(2-n)} D^{(4 n-2) /(2-n)}}\right]\left(\mathrm{Re}_{-} n\right)^{(1+n) /(2-n)} & \text { laminar flow } \\
\dot{S}_{G}^{\prime}=\left(\frac{\pi}{2 T}\right)\left[\frac{\left(a_{n}\right)^{3 /(2-n)}}{\rho^{(1+n) /(2-n)} D^{(4 n-2) /(2-n)}}\right] \alpha_{n}\left(\mathrm{Re}_{-} n\right)^{(3 /(2-n))-\beta_{n}} & \text { turbulent flow }
\end{array}
$$

where $a_{n}$ is given by Equation (18), $\alpha_{n}$ by Equation (24), and $\beta_{n}$ by Equation (25). Equations (27) and (28) are the new predictive models for entropy generation per unit length in pipeline flow of non-Newtonian power-law fluids. These models could be applied to non-Newtonian (power-law) pseudo-homogeneous mixtures of two phases such as emulsions of oil and water. When the fluid is Newtonian, $n=1, K=\mu$, these expressions reduce to:

$$
\begin{array}{cc}
\dot{S}_{G}^{\prime}=\frac{\pi}{2 T}\left(\frac{\mu^{3}}{\rho^{2} D^{2}}\right)\left(16 \mathrm{Re}^{2}\right) & \text { laminar flow } \\
\dot{S}_{G}^{\prime}=\frac{\pi}{2 T}\left(\frac{\mu^{3}}{\rho^{2} D^{2}}\right)\left(0.078 \mathrm{Re}^{2.75}\right) & \text { turbulent flow }
\end{array}
$$

Equations (29) and (30) were derived in our previous study [23] on entropy generation in pipeline flow of Newtonian emulsions. 


\section{Model Predictions}

Figure 1 shows the effect of flow behavior index $n$ on entropy generation rate in flow of non-Newtonian power-law fluids in a smooth tube. The plots of $\dot{S}_{G}^{\prime}$ versus Re_ $n$ are generated from model Equations (27) and (28) for different values of $n$. The tube diameter is $26.54 \mathrm{~mm}$ and the fluid properties are as follows: $\rho=1000 \mathrm{~kg} / \mathrm{m}^{3}$ and $K=0.1 P a . s^{n}$. The figure indicates that: (a) for a given value of $n$, the entropy generation rate $\dot{S}_{G}^{\prime}$ increases linearly with the increase in generalized Reynolds number on a log-log scale, in both laminar and turbulent regimes. However, the slope in the turbulent regime is higher; (b) for a given value of $\mathrm{Re}_{-} n$, the entropy generation rate per unit tube length increases with the increase in the value of the flow behavior index $n$. This indicates that flow of pseudo-plastic fluids $(n<1)$ is more efficient thermodynamically in comparison with dilatant fluids $(n>1)$.

Figure 1. $\dot{S}_{G}^{\prime}$ versus $\mathrm{Re}_{-} n$ plots for non-Newtonian power-law fluids for different values of flow behavior index $n$.

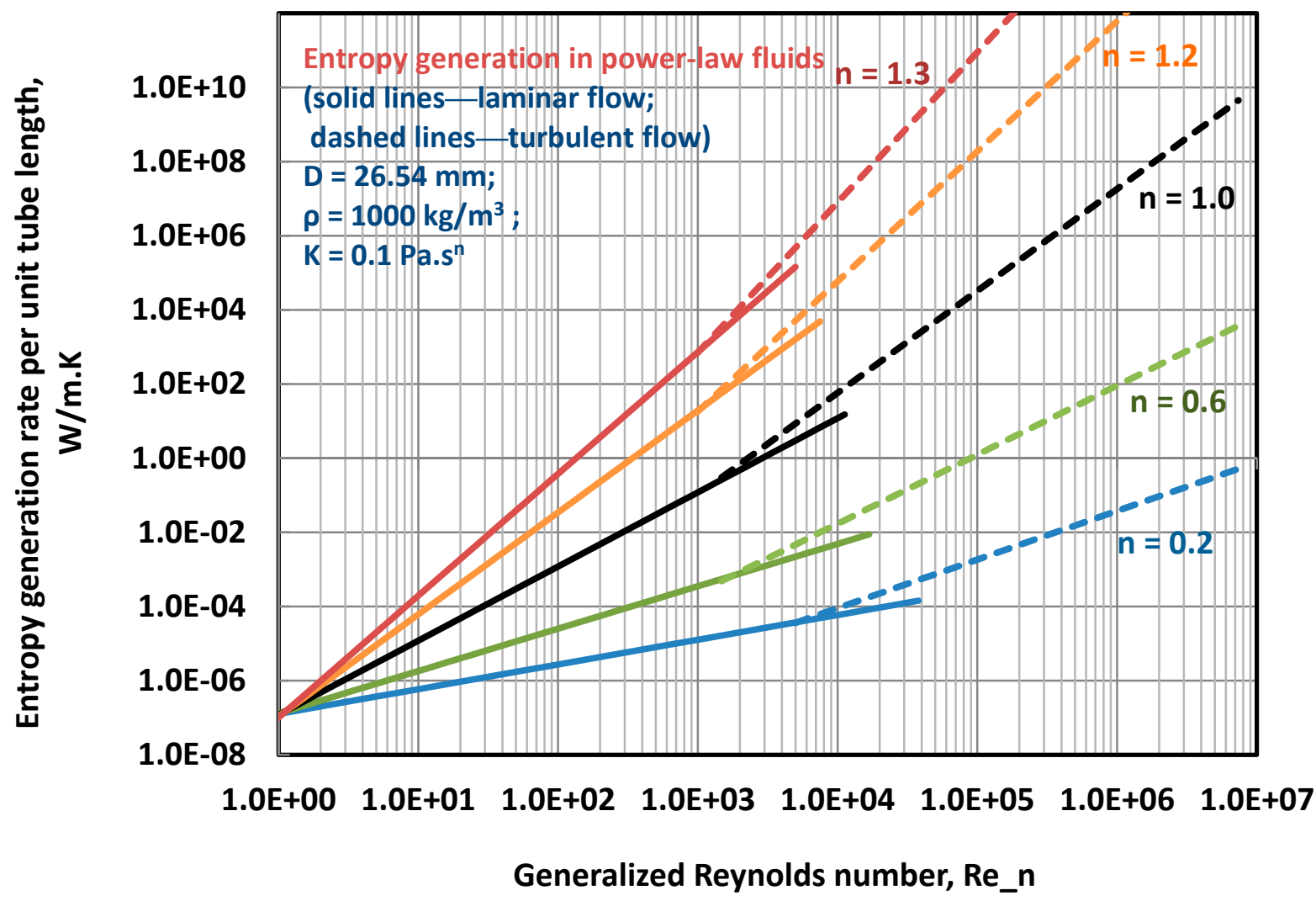

The influence of consistency index $K$ on entropy generation rate in flow of power-law fluids in a smooth tube is shown in Figure 2. The plots of $\dot{S}_{G}^{\prime}$ versus $\mathrm{Re}_{-} n$ shown in the figure are generated from model Equations (27) and (28) for different values of $K$. The tube diameter is $26.54 \mathrm{~mm}$ and the fluid properties are as follows: $\rho=1000 \mathrm{~kg} / \mathrm{m}^{3}$ and $n=0.6$. With the increase in $K$, a constant upward shift is observed in the plot of $\dot{S}_{G}^{\prime}$ versus Re_ $n$. This indicates that for a given value of Re_ $n$, the entropy generation rate per unit tube length increases with the increase in $K$ value. 
Figure 2. $\dot{S}_{G}^{\prime}$ versus $\mathrm{Re}_{-} n$ plots for non-Newtonian power-law fluids for different values of consistency index $K$.

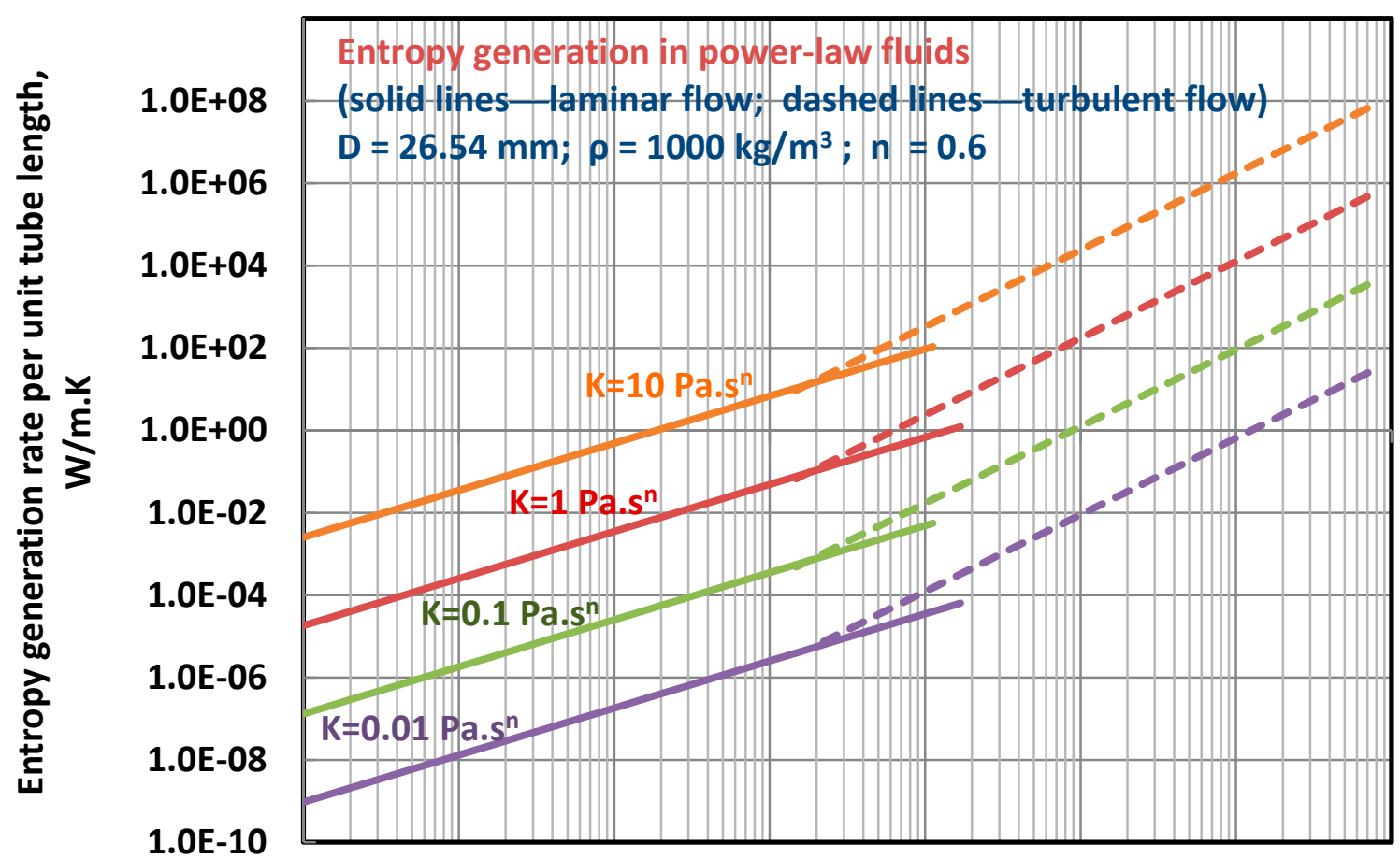

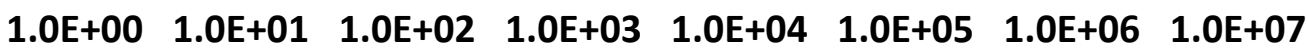
Generalized Reynolds number, Re_n

\section{Experimental Work}

Figure 3 shows a schematic diagram of the flow rig that was designed and developed to experimentally investigate of the rate of entropy generation in flow of emulsions in smooth tubes. Five different diameter tubes (stainless steel, seamless) were installed horizontally. The various dimensions of the test sections are summarized in Table 1. The emulsions were prepared in a large mixing tank (capacity about $1 \mathrm{~m}^{3}$ ) equipped with baffles, two high shear mixers, heating/cooling coil, and a temperature controller. The emulsion from the mixing tank was circulated to the tube test sections, one at a time, by a centrifugal pump. From the tube test section, the emulsion was allowed to return to the mixing tank via the metering section where its flow rate was measured.

The pressure drops in various tubes were measured by means of pressure transducers. The output signals from the pressure transducers were recorded by a microcomputer data-acquisition system. Further details about the flow rig can be found in our earlier publication [23].

The emulsions were prepared using $1 \%$ by wt. surfactant solution in tap water and a refined mineral oil (Bayol-35). Triton X-100 (isooctylphenoxypolyethoxy ethanol) was used as a surfactant. This is a water soluble non-ionic surfactant. The oil had a density of $780 \mathrm{~kg} / \mathrm{m}^{3}$ and a viscosity of $2.41 \mathrm{mPa}$.s at $25^{\circ} \mathrm{C}$. The oil-in-water emulsions of three different dispersed phase (oil) concentrations were prepared; the dispersed phase concentrations were $59.61 \%, 65.15 \%$, and $72.21 \%$ by volume. The emulsions produced were highly stable with respect to coalescence. 
A Fann coaxial cylinder viscometer was used to determine the rheological behavior (shear stress versus shear rate) of emulsions. The droplet size information of emulsion was obtained by taking photomicrographs with a Zeiss optical microscope.

The experimental work was conducted at a constant temperature of $25{ }^{\circ} \mathrm{C}$. The temperature was maintained constant in the flow loop with the help of a temperature controller installed in the mixing tank.

Figure 3. Schematic diagram of the flow rig.

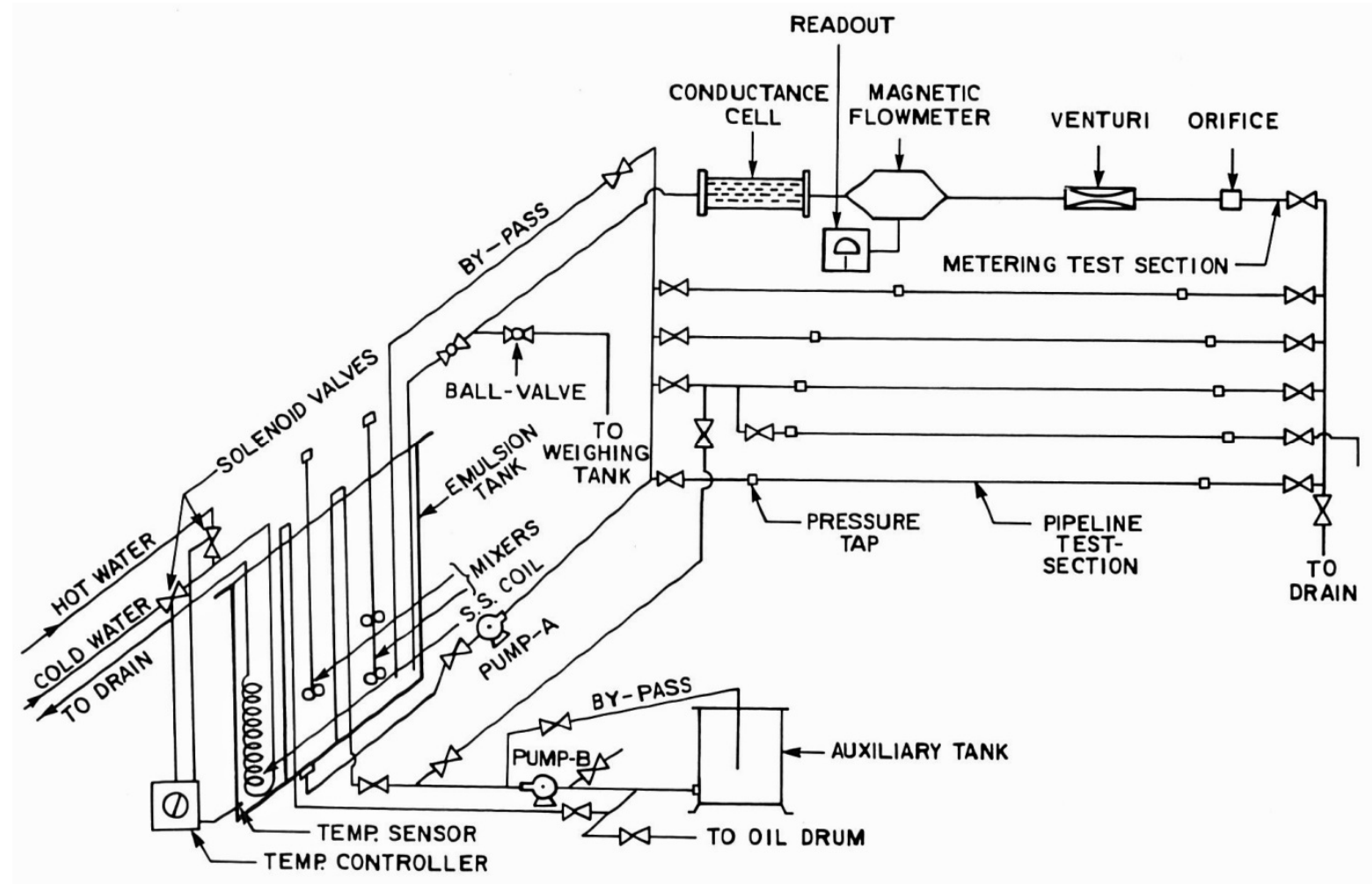

Table 1. Various dimensions of tube test sections.

\begin{tabular}{cccc}
\hline $\begin{array}{c}\text { Tube inside diameter } \\
{[\mathbf{m m}]}\end{array}$ & $\begin{array}{c}\text { Entrance length } \\
{[\mathbf{m}]}\end{array}$ & $\begin{array}{c}\text { Length of test section } \\
{[\mathbf{m}]}\end{array}$ & $\begin{array}{c}\text { Exit length } \\
{[\mathbf{m}]}\end{array}$ \\
\hline 7.15 & 1.07 & 3.05 & 0.46 \\
8.89 & 0.89 & 3.35 & 0.48 \\
12.60 & 1.19 & 2.74 & 0.53 \\
15.80 & 1.65 & 2.59 & 0.56 \\
26.54 & 3.05 & 1.22 & 0.67 \\
\hline
\end{tabular}

\section{Experimental Results and Discussion}

Figure 4 shows typical photomicrographs of oil droplets of an emulsion. The droplets are smaller than $12 \mu \mathrm{m}$ in diameter. The viscosity versus shear rate plots of emulsions are shown in Figures 5-7.

The apparent viscosity $\mu$, defined as the ratio of shear stress $(\tau)$ to shear rate $(\dot{\gamma})$, decreases with the increase in shear rate indicative of shear-thinning non-Newtonian behavior of emulsions. The plots of $\mu$ versus $\dot{\gamma}$ follow a linear relationship on a log-log scale indicating that emulsions follow a power-law model (Equation (16)). Note that the power-law model (Equation (16)) could be expressed as: 


$$
\log \mu=\log K-(1-n) \log \dot{\gamma}
$$

Thus, the slope is of $\mu$ versus $\dot{\gamma}$ plot is negative, equal to $-(1-n)$. According to plots of Figures 5-7, the power-law index $n$ decreases and the consistency index $K$ increases with the increase in dispersed-phase (oil) concentration. The variations of $n$ and $K$ with the dispersed-phase concentration of emulsion can be seen more clearly in Figures 8 and 9. Interestingly, the power law constants $n$ and $K$ undergo dramatic changes when the oil concentration of the emulsion is increased from $65.15-72.21 \%$ vol.

Figure 4. Typical photomicrographs of emulsion.
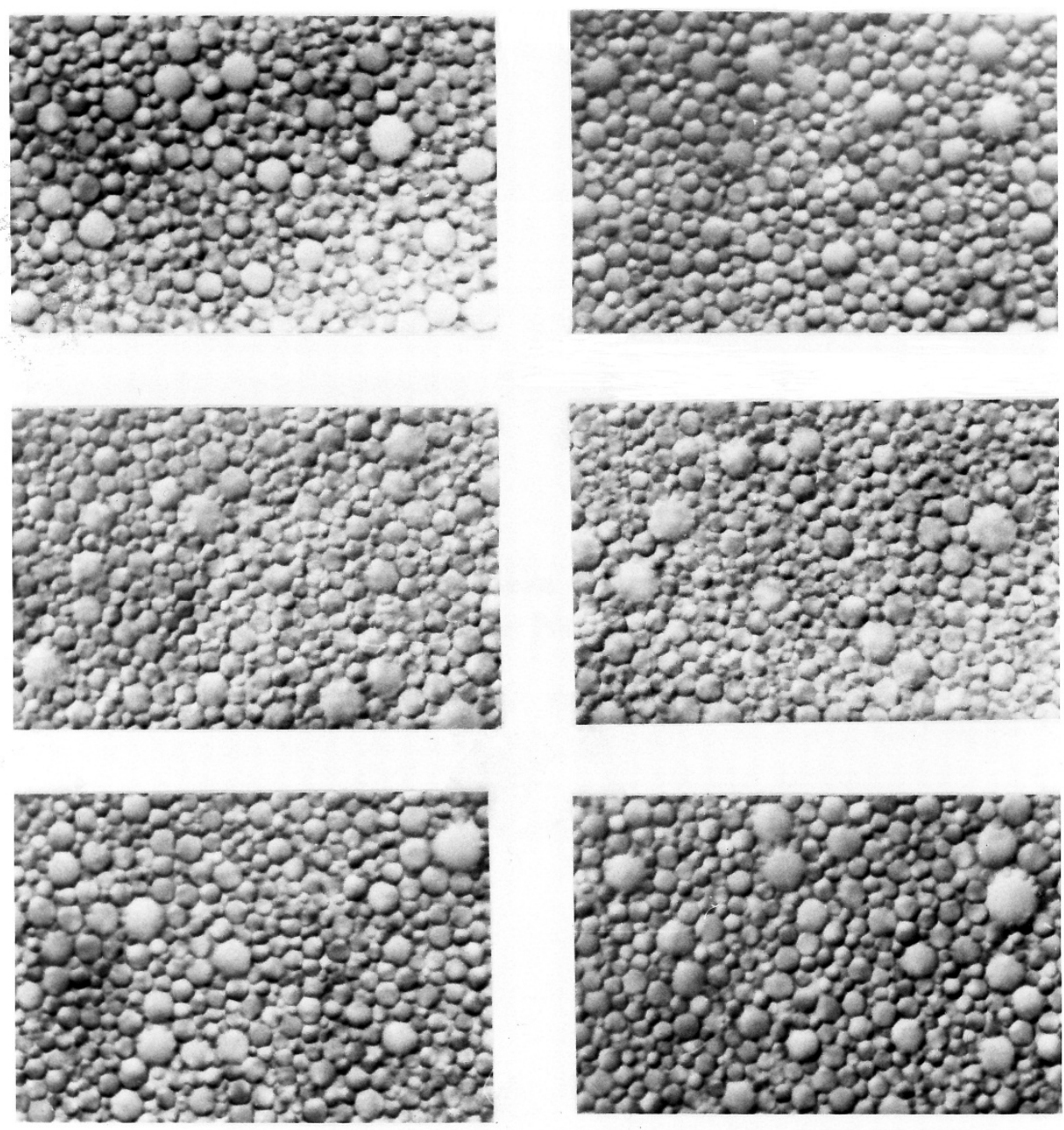

$12 \mu \mathrm{m}$ 
Figure 5. Apparent viscosity versus shear rate plot for 59.61\% vol. O/W emulsion.

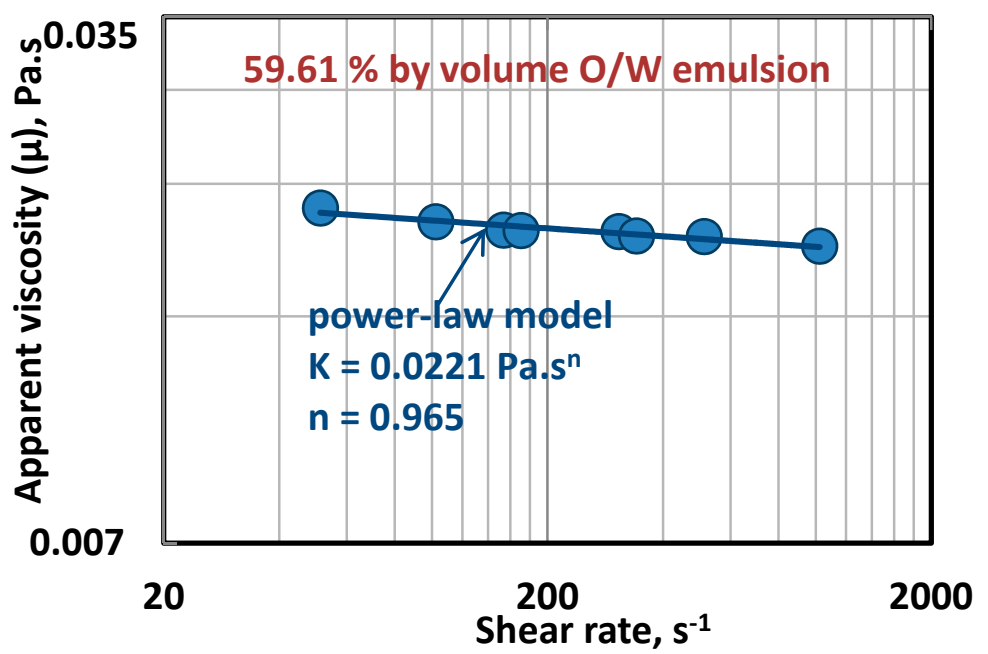

Figure 6. Apparent viscosity versus shear rate plot for $65.15 \%$ vol. O/W emulsion.

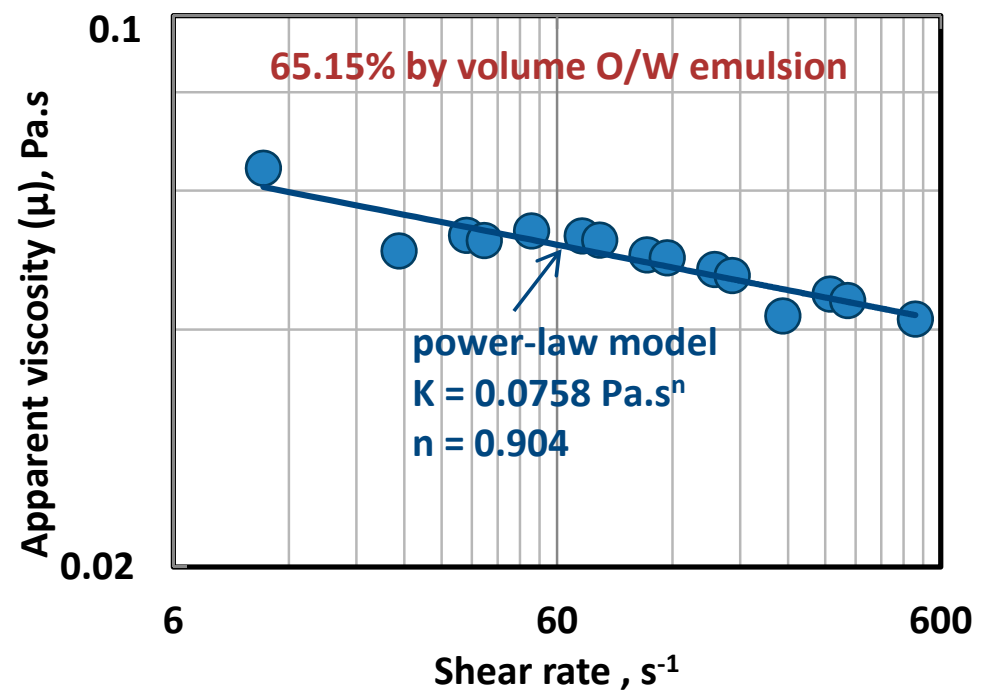

Figure 7. Apparent viscosity versus shear rate plot for $72.21 \%$ vol. $\mathrm{O} / \mathrm{W}$ emulsion.

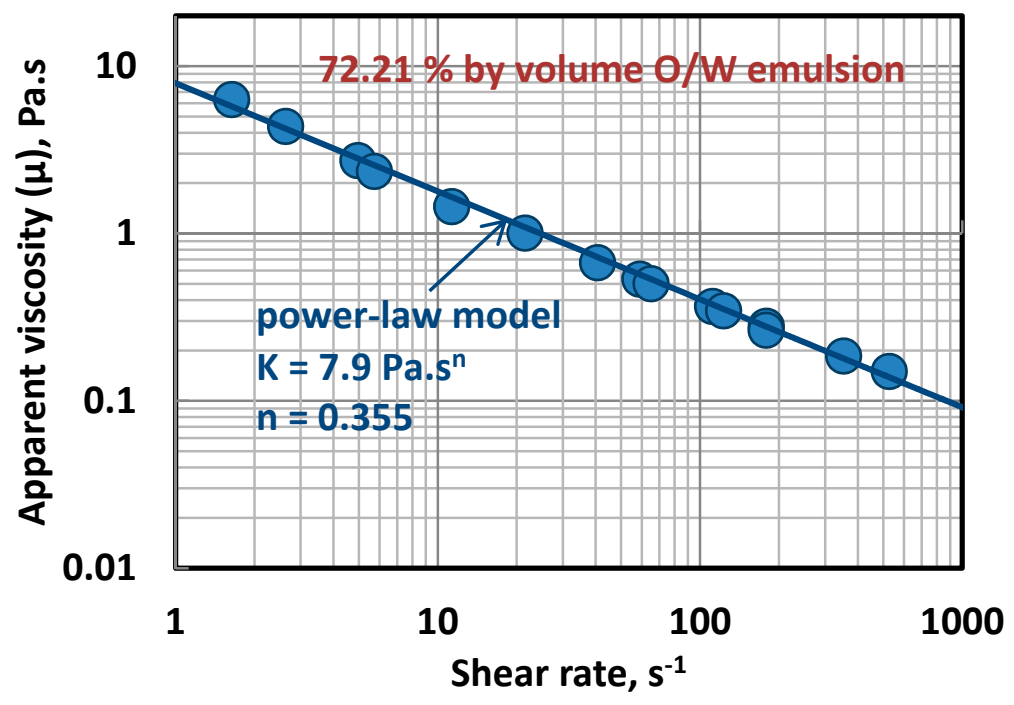


Figure 8. Variation of flow behavior index $n$ with the increase in dispersed phase concentration of $\mathrm{O} / \mathrm{W}$ emulsion.

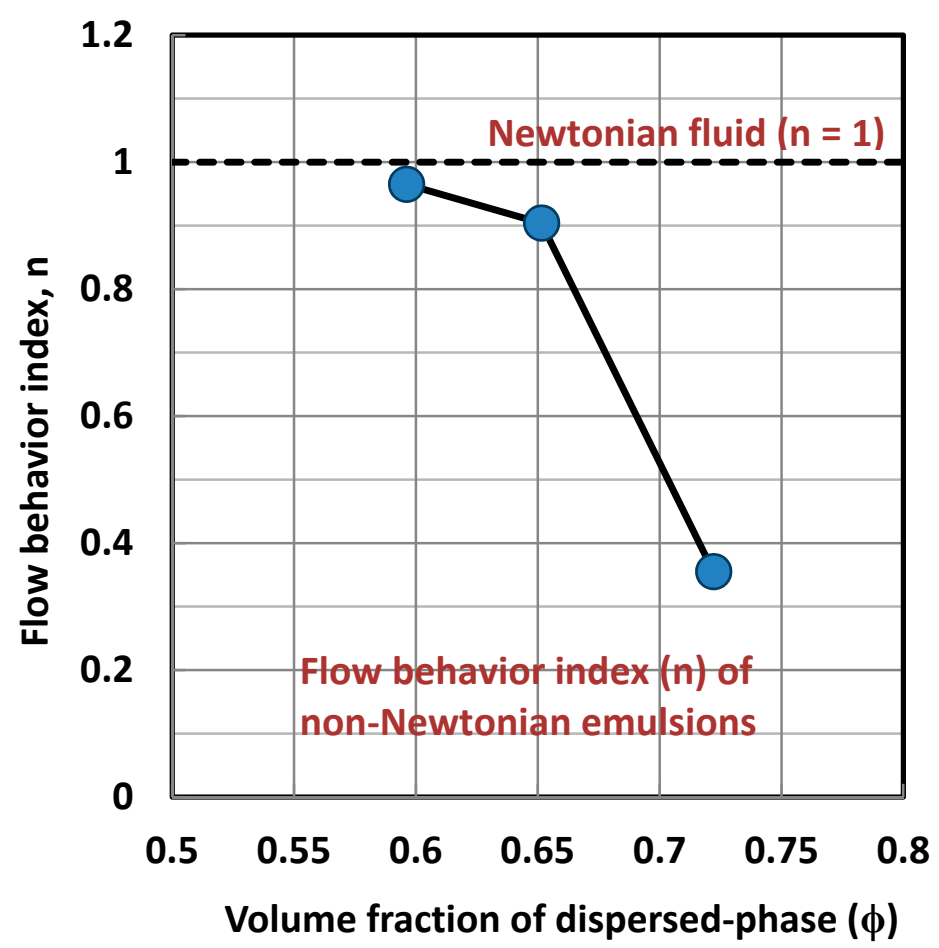

Figure 9. Variation of consistency index $K$ with the increase in dispersed phase concentration of $\mathrm{O} / \mathrm{W}$ emulsion.

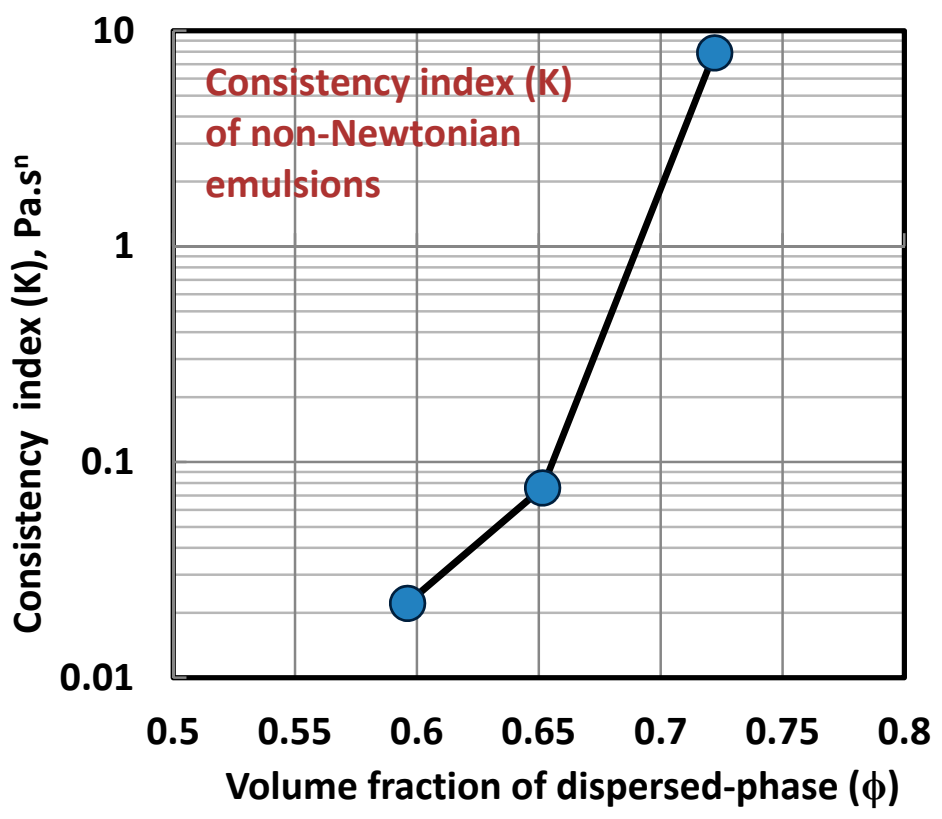

Figure 10 shows the plots of $\dot{S}_{G}^{\prime}$ versus Re_ $n$ data for $59.61 \%$ vol. O/W emulsion in different diameter tubes. For a given diameter tube, the entropy generation rate $\dot{S}_{G}^{\prime}$ increases linearly with the increase in the generalized Reynolds number $\left(\operatorname{Re}_{-} n\right)$ on a log-log plot. As expected, the slope of $\dot{S}_{G}^{\prime}$ versus $\mathrm{Re}_{-} n$ plot is higher in the turbulent regime. With the increase in tube diameter, the entropy generation rate per unit tube length decreases at any given value of the generalized Reynolds number. 
Also, the experimental data shows excellent agreement with the predictions of the models. The solid lines shown in Figure 10 are the predictions of laminar model (Equation (27)) and the dashed lines represent the predictions of turbulent model (Equation (28)).

Figure 10. $\dot{S}_{G}^{\prime}$ versus $\mathrm{Re}_{-} n$ plots for $59.61 \%$ vol. O/W emulsion flow in different diameter tubes. The solid lines in the laminar region represent Equation (27) and the dashed lines in the turbulent region represent Equation (28).

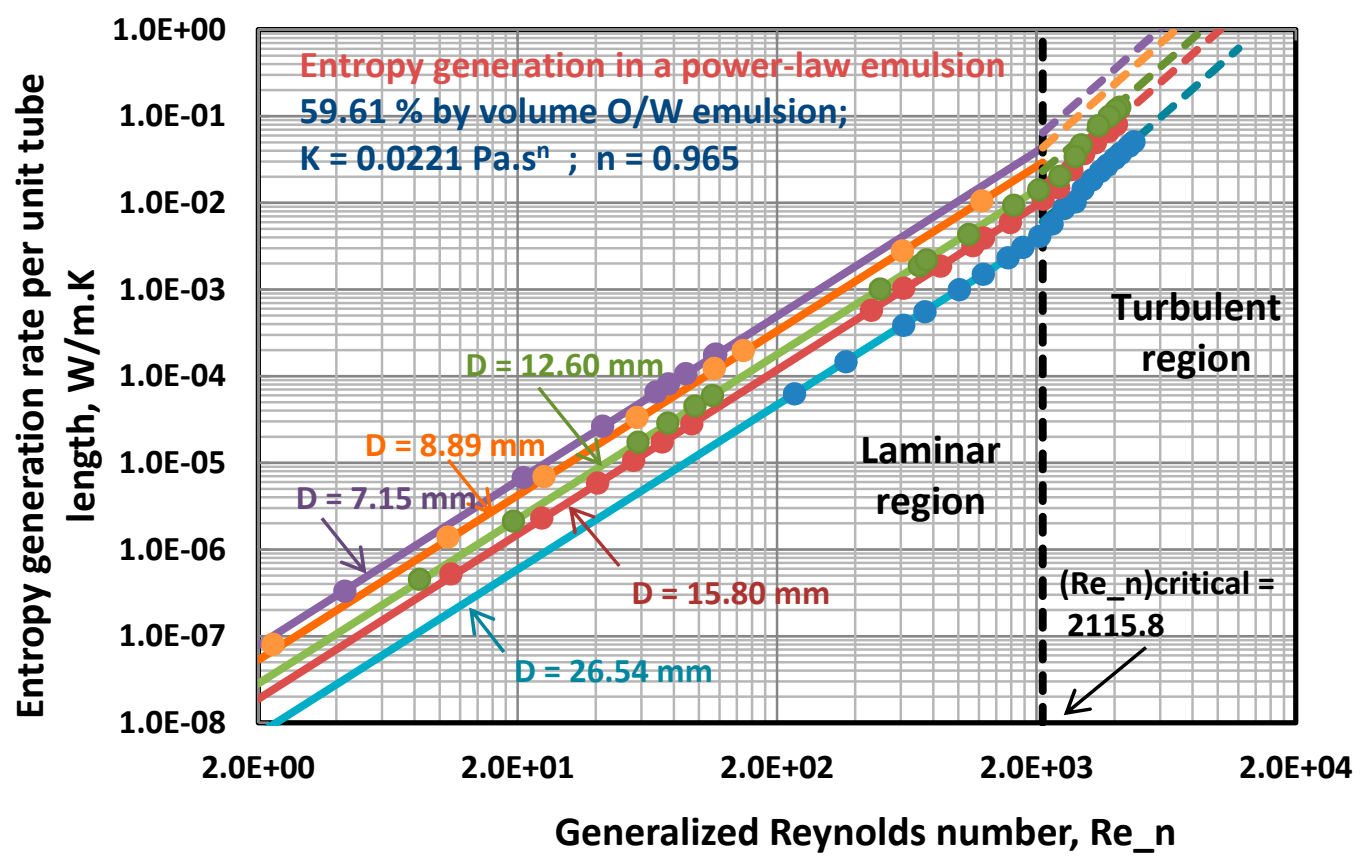

Figures 11 and 12 show the plots of $\dot{S}_{G}^{\prime}$ versus $\mathrm{Re}_{-} n$ data for $65.15 \%$ and $72.21 \%$ vol. O/W emulsions, respectively. Due to the highly viscous nature of these emulsions, turbulent flow could not be achieved in our experiments and the data are restricted to laminar regime only. The plots of $\dot{S}_{G}^{\prime}$ versus $\mathrm{Re}_{-} n$ data are linear (log-log scale) and the experimental data show good agreement with the predictions of the model, see Equation (27). It is interesting to note that in the case of $72.21 \%$ vol. $\mathrm{O} / \mathrm{W}$ emulsion, the diameter dependence of entropy generation rate $\dot{S}_{G}^{\prime}$ is opposite to that of the other emulsions with lower volume fraction of dispersed-phase. The entropy generation rate $\dot{S}_{G}^{\prime}$ increases with the increase in tube diameter for $72.21 \%$ vol. $\mathrm{O} / \mathrm{W}$ emulsion whereas the other emulsions with lower concentration exhibit a decrease in $\dot{S}_{G}^{\prime}$ with the increase in tube diameter at a given Re_ $n$. According to the models, Equations (27) and (28):

$$
\dot{S}_{G}^{\prime} \propto D^{-(4 n-2) /(2-n)}
$$

When $n=0.5$, Equation (32) predicts $\dot{S}_{G}^{\prime}$ to be independent of the tube diameter. When $n>0.5, \dot{S}_{G}^{\prime}$ is expected to decrease with the increase in tube diameter as $(4 n-2) /(2-n)>0$; for Newtonian fluid $(n=1),(4 n-2) /(2-n)=2$. When $n<0.5, \dot{S}_{G}^{\prime}$ is expected to increase with the increase in tube diameter as $(4 n-2) /(2-n)<0$; for the case of extreme pseudo-plasticity $(n=0),(4 n-2) /(2-n)=-1$ and $\dot{S}_{G}^{\prime} \propto D$, that is, $\dot{S}_{G}^{\prime}$ is directly proportional to the tube diameter. 
Figure 11. $\dot{S}_{G}^{\prime}$ versus $\mathrm{Re}_{-} n$ plots for $65.15 \%$ vol. O/W emulsion flow in different diameter tubes. The solid lines represent Equation (27).

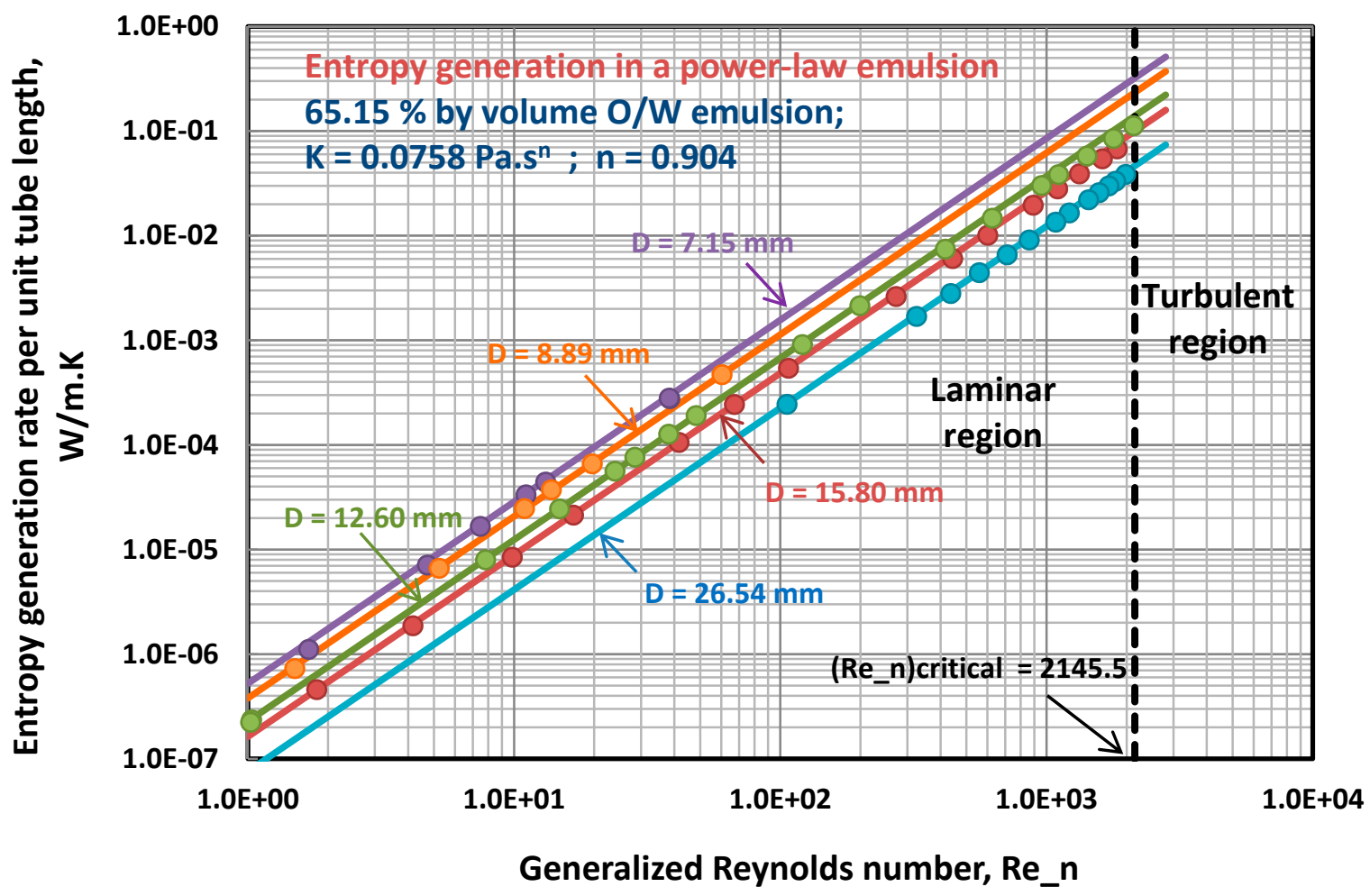

Figure 12. $\dot{S}_{G}^{\prime}$ versus $\mathrm{Re}_{-} n$ plots for $72.21 \%$ vol. O/W emulsion flow in different diameter tubes. The solid lines represent Equation (27).

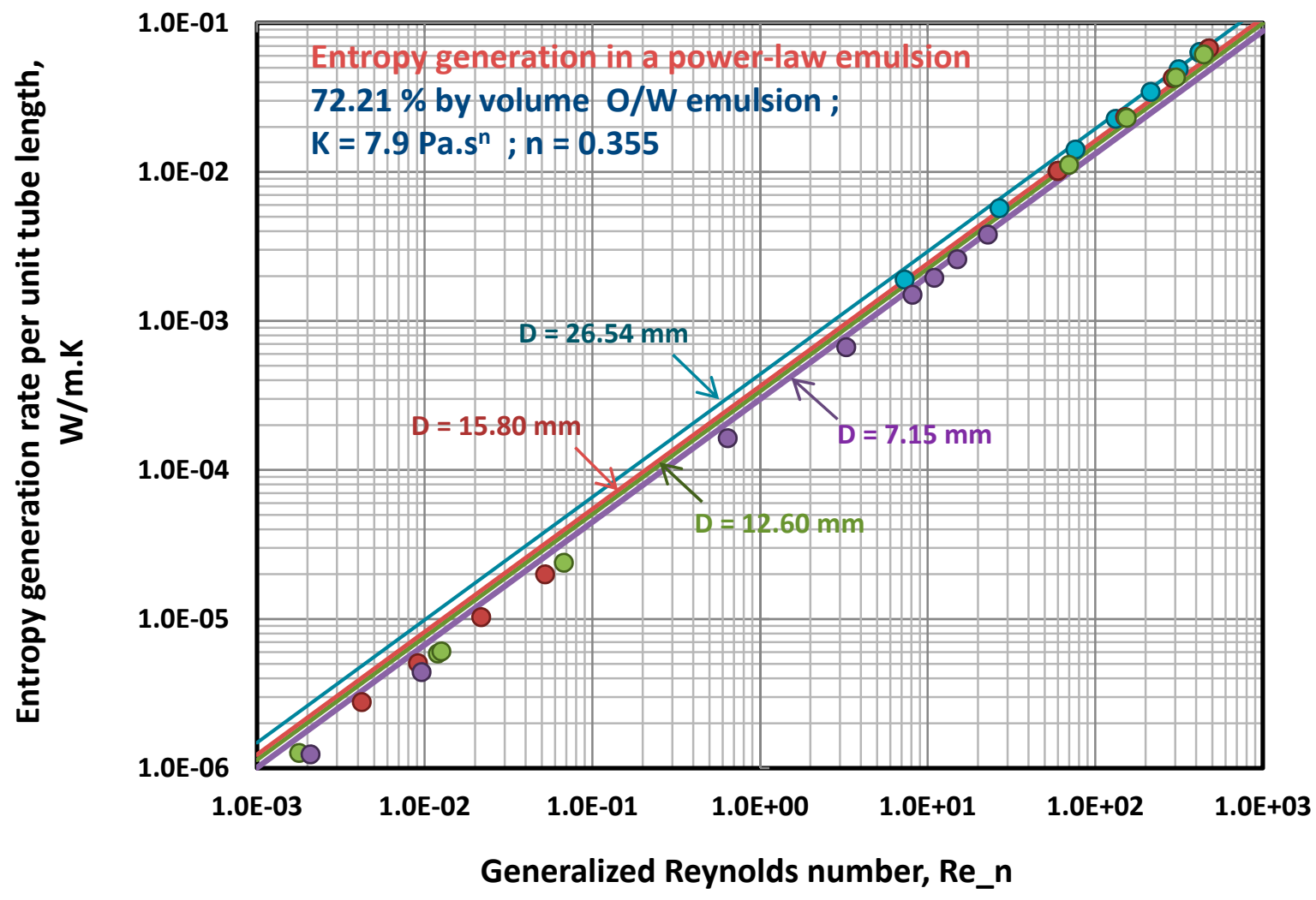


Figures 13-15 confirm the diameter-dependence of $\dot{S}_{G}^{\prime}$ expressed in Equation (32). The experimental data are now re-plotted as $D^{(4 n-2) /(2-n)} \dot{S}_{G}^{\prime}$ versus $\mathrm{Re} \_n$. As expected, the experimental data for a given emulsion from different diameter tubes fall on the same curve. The solid lines shown in the figures are generated from the model equations: Equations (27) for laminar flow and Equation (28) for turbulent flow. There is good agreement between experimental data and model predictions.

Figure 16 compares the plots of $D^{(4 n-2) /(2-n)} \dot{S}_{G}^{\prime}$ versus $\mathrm{Re}_{-} n$ for different emulsions. The experimental data from all the tubes are included. At any given value of the generalized Reynolds number $\left(\operatorname{Re}_{-} n\right)$, the diameter-scaled entropy generation rate $\left(D^{(4 n-2) /(2-n)} \dot{S}_{G}^{\prime}\right)$ of $\mathrm{O} / \mathrm{W}$ emulsion increases with the increase in the dispersed-phase $(\phi)$ concentration. While the increase in entropy generation rate is modest when $\phi$ increases from 59.61-65.15\% vol., a large increase in entropy generation rate is observed when $\phi$ increases from $65.15-72.21 \%$ vol.

At a high dispersed-phase concentration of $72.21 \%$ vol., the dispersed (oil) droplets of emulsion are jam packed and consequently the emulsion behaves as a very viscous material with high rates of entropy generation. The theoretical value of the dispersed-phase concentration corresponding to hexagonal close packing of spheres is $74 \%$ vol. Thus, emulsions are expected to behave more like a semi-solid material with significant yield stress when $\phi$ is increased above $74 \%$ vol.

Figure 13. $D^{(4 n-2) /(2-n)} \dot{S}_{G}^{\prime}$ versus $\mathrm{Re}_{-} n$ plot for $59.61 \%$ vol. O/W emulsion flow in different diameter tubes $\left(n=0.965, K=0.0221 \mathrm{~Pa} \mathrm{~s}^{n}\right)$. The solid line in the laminar region represents Equation (27) and the solid line in the turbulent region represents Equation (28). The colored circles represent experimental data from different diameter tubes.

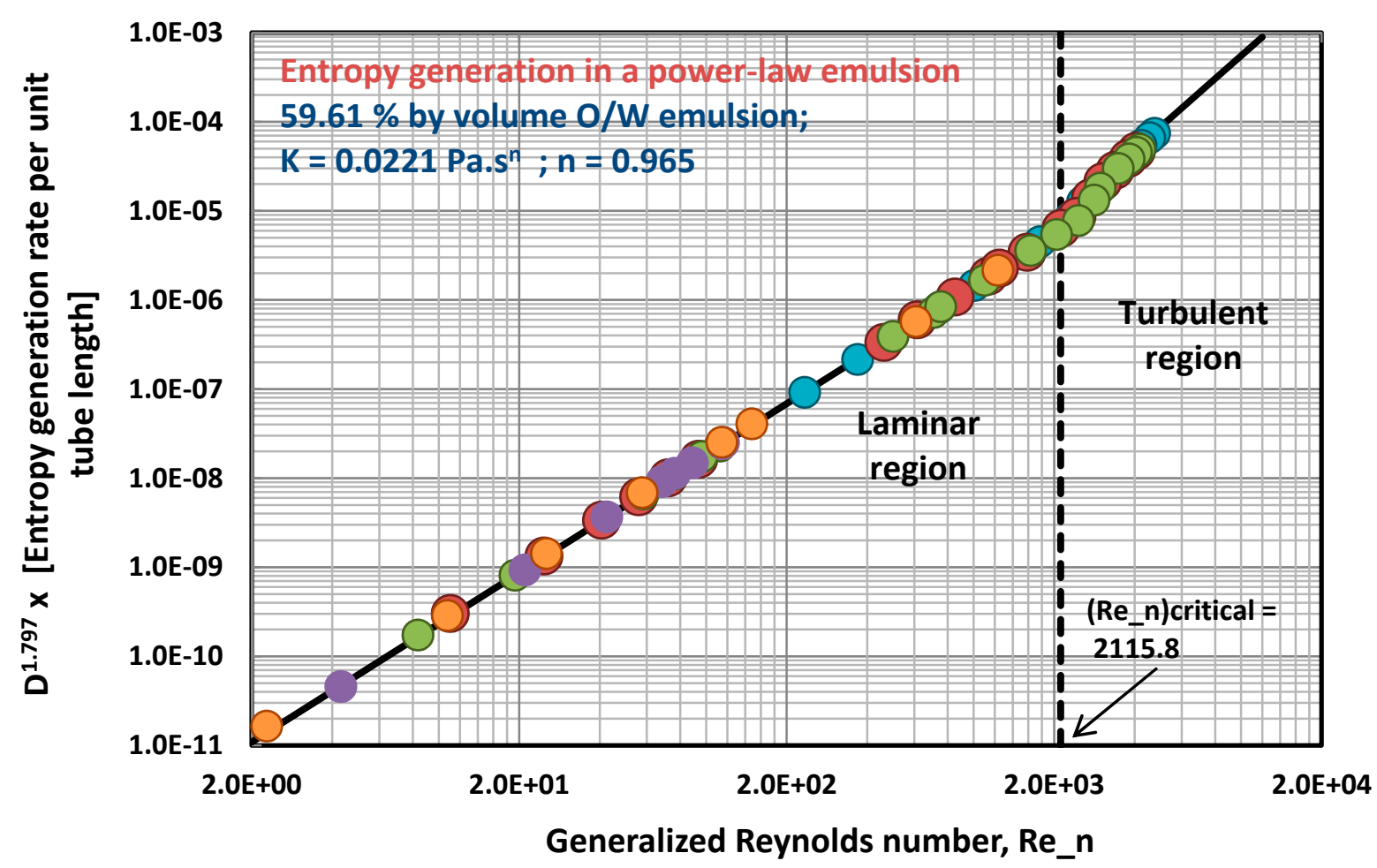


Figure 14. $D^{(4 n-2) /(2-n)} \dot{S}_{G}^{\prime}$ versus $\mathrm{Re}_{-} n$ plot for $65.15 \%$ vol. O/W emulsion flow in different diameter tubes $\left(n=0.904, K=0.0758 \mathrm{~Pa}^{\mathrm{n}} \mathrm{s}^{\mathrm{n}}\right)$. The solid line represents Equation (27). The colored circles represent experimental data from different diameter tubes.

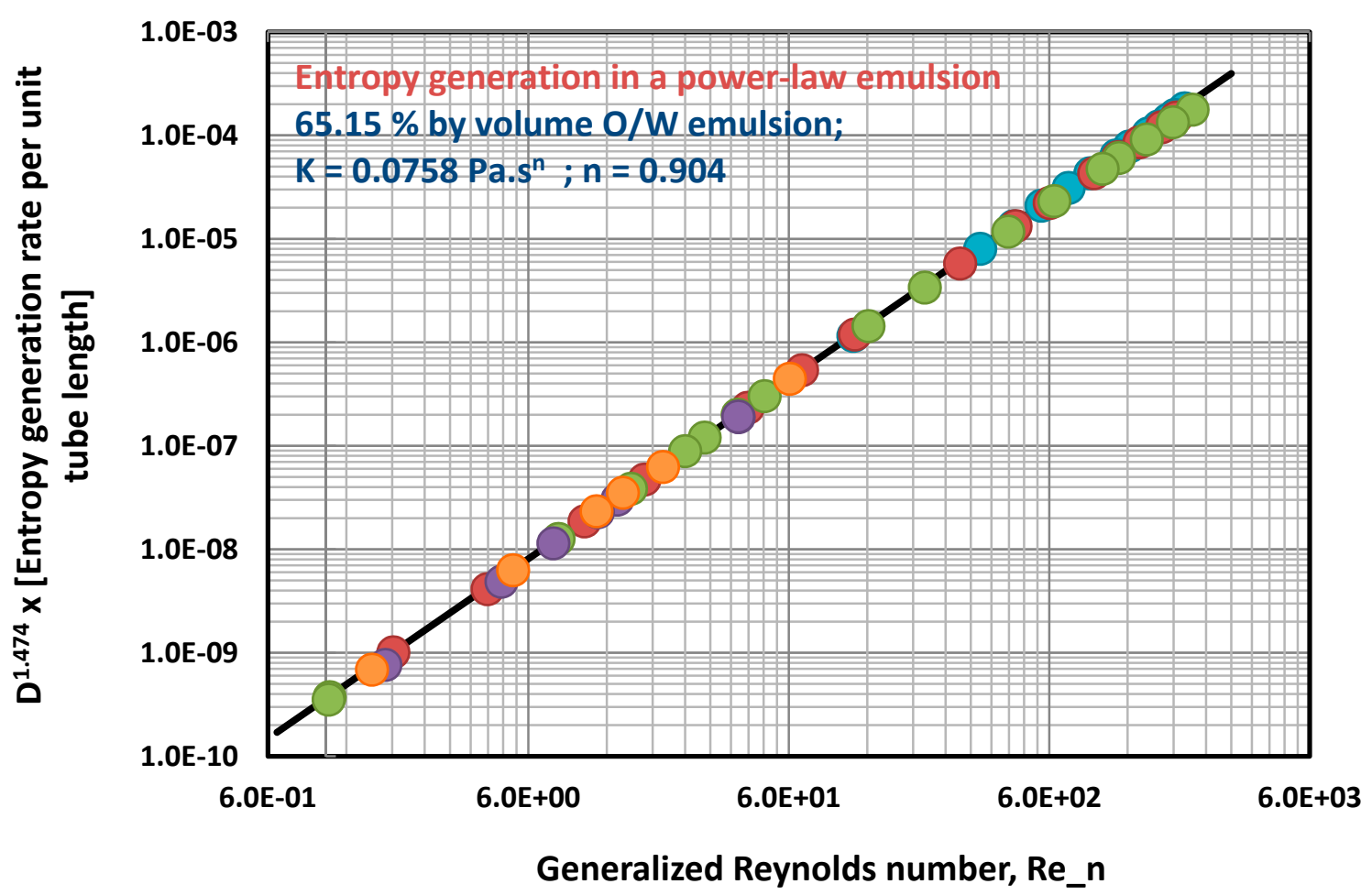

Figure 15. $D^{(4 n-2) /(2-n)} \dot{S}_{G}^{\prime}$ versus $\mathrm{Re}$. $n$ plot for $72.21 \%$ vol. O/W emulsion flow in different diameter tubes $\left(n=0.355, K=7.9\right.$ Pa.s $^{n}$ ). The solid line represents Equation (27). The colored circles represent experimental data from different diameter tubes.

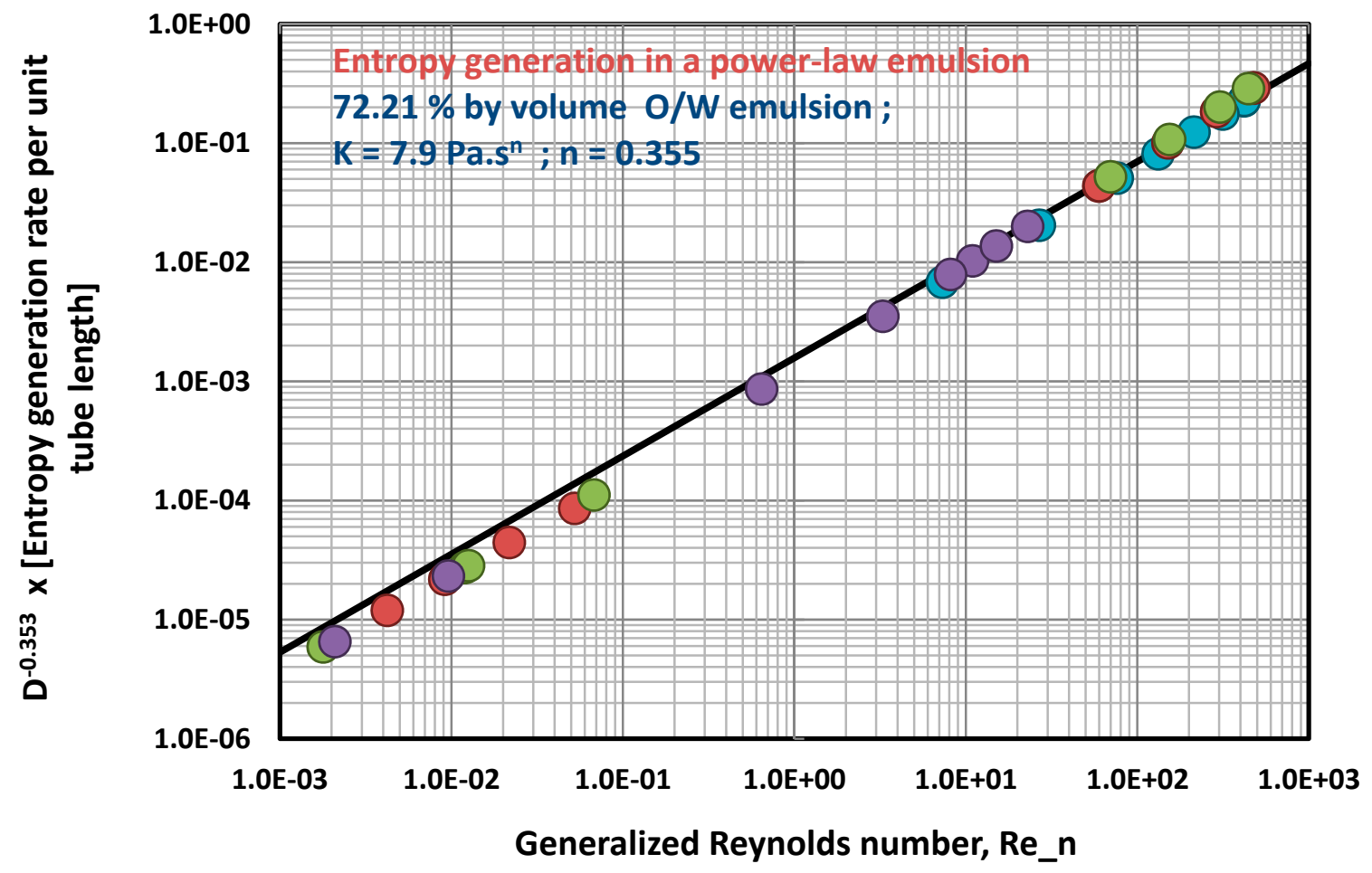


Figure 16. Comparison of $D^{(4 n-2) /(2-n)} \dot{S}_{G}^{\prime}$ versus $\mathrm{Re}_{-} n$ plots for $\mathrm{O} / \mathrm{W}$ emulsions with different dispersed-phase concentrations. The solid lines represent Equation (27) (laminar flow) and Equation (28) (turbulent flow). The colored circles represent experimental data.

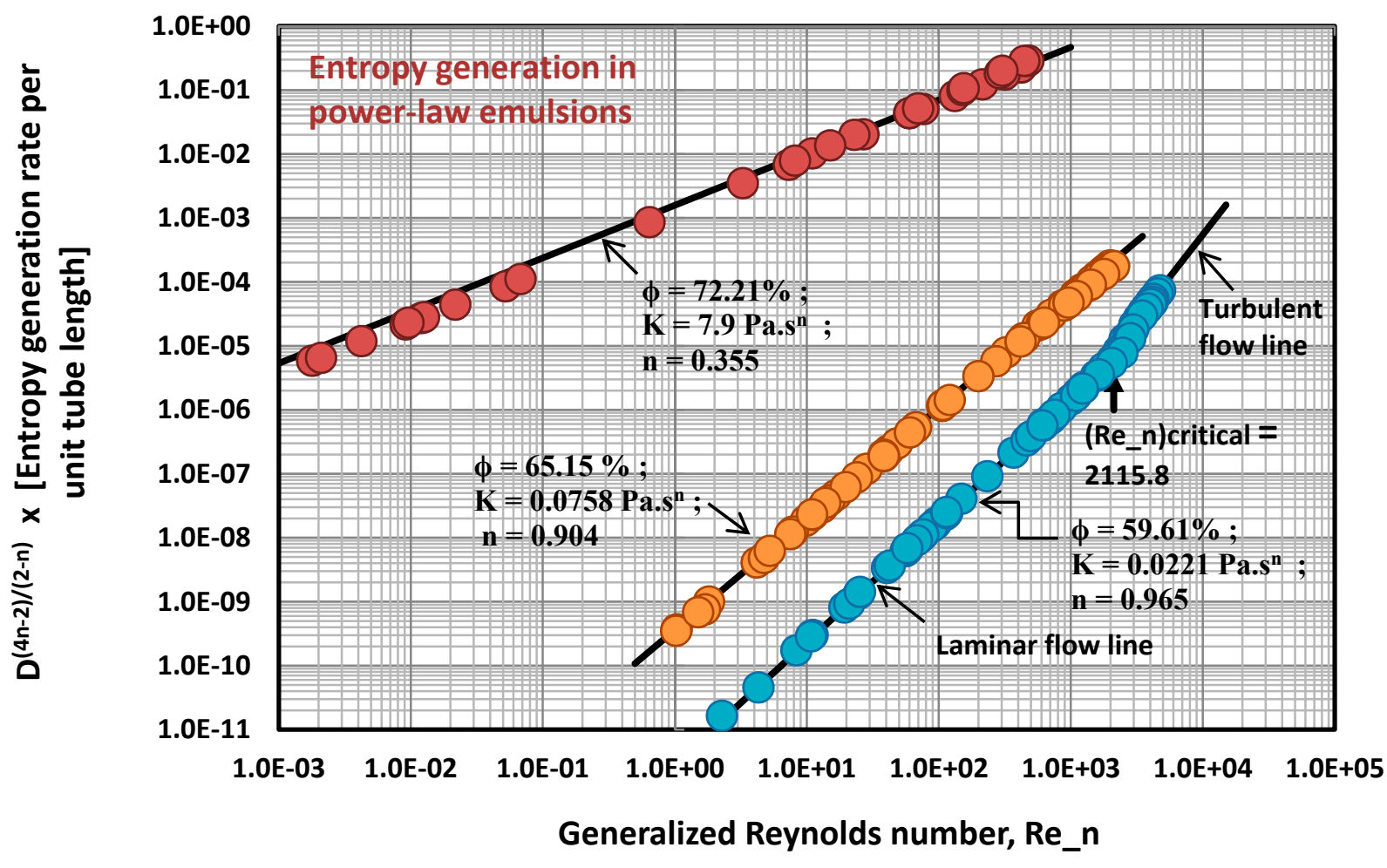

\section{Conclusions}

Entropy production in adiabatic flow of non-Newtonian power-law emulsions of oil-in-water type in smooth tubes was investigated experimentally and theoretically. Based on this study, the following conclusions can be made: (a) for a given power-law emulsion ( $K$ and $n$ fixed), the entropy generation rate $\dot{S}_{G}^{\prime}$ in a given diameter tube increases linearly with the increase in generalized Reynolds number on a log-log scale, in both laminar and turbulent regimes. However, the slope in the turbulent regime is higher; (b) at a given value of the generalized Reynolds number Re_ $n$, the entropy generation rate per unit tube length increases with the increase in the value of the flow behavior index $n$, keeping other factors ( $K$ and $D$ ) constant; (c) at a given value of $\mathrm{Re}_{-} n$, the entropy generation rate per unit tube length increases with the increase in $K$ value, keeping other factors ( $n$ and $D$ ) constant; (d) the power-law constants ( $n$ and $K$ ) undergo dramatic changes when the dispersed-phase concentration of the $\mathrm{O} / \mathrm{W}$ emulsion is increased from $65.15 \%-72.21 \%$ vol.; $n$ drops whereas $K$ rises sharply; (e) emulsions with dispersed-phase concentration $(\phi) \leq 65.15 \%$ exhibit inverse diameter-dependency in that the entropy generation rate decreases with the increase in tube diameter whereas emulsion with $\phi=72.21 \%$ vol. shows direct diameter-dependency in that the entropy generation rate increases with the increase in tube diameter; (f) the diameter-scaled entropy generation rate increases sharply when $\phi$ is increased from $65.15 \%-72.21 \%$ vol.; and $(\mathrm{g})$ the models proposed for entropy generation rate in flow of power-law fluids in tubes describe the experimental data for power-law emulsions reasonably well. 


\section{Acknowledgment}

Financial support from the Natural Sciences and Engineering Research Council of Canada is appreciated.

\section{Conflicts of Interest}

The author declares no conflict of interest.

\section{References}

1. Bejan, A. Entropy Generation Minimization: The Method of Thermodynamic Optimization of Finite-Size Systems and Finite-Time Processes; CRC Press: Boca Raton, FL, USA, 1996; Chapter 2.

2. Abbott, M.M.; van Ness, H.C. Theory and Problems of Thermodynamics, 2nd ed.; Schaum's Outline Series; McGraw-Hill: New York, NY, USA, 1989; Chapter 8.

3. Cengel, Y.; Boles, M. Thermodynamics: An Engineering Approach, 7th ed.; McGraw-Hill: New York, NY, USA, 2011; Chapter 8.

4. Smith, J.M.; van Ness, H.C.; Abbott, M.M. Introduction to Chemical Engineering Thermodynamics, 7th ed.; McGraw-Hill: New York, NY, USA, 2005; Chapter 5.

5. Pal, R. Rheology of Particulate Dispersions and Composites; CRC Press: Boca Raton, FL, USA, 2007; Chapter 8.

6. Marsden, S.S.; Raghavan, R. A system for producing and transporting crude oil as an oil/water emulsion. J. Inst. Pet. 1973, 59, 273-278.

7. Zakin, J.L.; Pinaire, R.; Borgmeyer, M.E. Transportation of oils as oil-in-water emulsions. J. Fluids Eng. 1979, 101, 100-104.

8. Rimmer, D.P.; Gregoli, A.A.; Hamshar, J.A.; Yildrim, E. Pipeline emulsion transportation for heavy oils. In Emulsions: Fundamentals and Applications in the Petroleum Industry; Schramm, L.L., Ed.; ACS Series 231; ACS: Washington, DC, USA, 1992; pp. 295-312.

9. Brauner, N.; Ullmann, A. Modeling of phase inversion phenomenon in two-phase pipe flows. Int. J. Multiph. Flow 2008, 28, 1177-1204.

10. Piela, K.; Delfos, R.; Ooms, G.; Westerweel, J.; Oliemans, R.V.A.; Mudde, R.F. Experimental investigation of phase inversion in an oil-water flow through a horizontal pipe loop. Int. J. Multiph. Flow 2006, 32, 1087-1099.

11. Piela, K.; Delfos, R.; Ooms, G.; Westerweel, J.; Oliemans, R.V.A. On the phase inversion process in an oil-water flow. Int. J. Multiph. Flow 2008, 34, 665-677.

12. Xu, J.Y.; Li, D.H.; Guo, J.; Wu, Y.X. Investigations of phase inversion and frictional pressure gradient in upward and downward oil-water flow in vertical pipes. Int. J. Multiph. Flow 2010, 36, 930-939.

13. Simmons, M.J.H.; Azzopardi, B.J. Drop size distribution in dispersed liquid-liquid pipe flow. Int. J. Multiph. Flow 2001, 27, 843-859.

14. Liao, Y.; Lucas, D. A literature review of theoretical models for drop and bubble breakup in turbulent dispersions. Chem. Eng. Sci. 2009, 64, 3389-3406. 
15. Jana, A.K.; Das, G.; Das, P.K. Flow regime identification of two-phase liquid-liquid upflow through vertical pipe. Chem. Eng. Sci. 2006, 61, 1500-1515.

16. Joseph, D.D.; Bai, R.; Chen, K.P.; Renardy, Y.Y. Core-annular flows. Annu. Rev. Fluid Mech. 1997, 29, 65-90.

17. Joseph, D.D.; Renardy, Y.Y. Fundamentals of Two-Fluid Dynamics. Part II: Lubricated Transport, Drops and Miscible Liquids; Interdisciplinary applied mathematics series, volume 4; Springer-Verlag: New York, NY, USA, 1993.

18. Lu, Y.; He, L.; He, Z.; Wang, A. A study of pressure gradient characteristics of oil-water dispersed flow in horizontal pipe. Energy Procedia 2012, 16, 1111-1117.

19. Pal, R. Pipeline flow of unstable and surfactant-stabilized emulsions. AIChE J. 1993, 39, 1754-1764.

20. Pal, R. Emulsion flow in pipelines. Int. J. Multiph. Flow 1989, 15, 1011-1017.

21. Hwang, C.Y.J.; Pal, R. Flow of two-phase oil/water mixtures through sudden expansions and contractions. Chem. Eng. J. 1997, 68, 157-163.

22. Pal, R. On the flow characteristics of highly concentrated oil-in-water emulsions. Chem Eng. J. 1990, 43, 53-57.

23. Pal, R. Entropy production in pipeline flow of dispersions of water in oil. Entropy 2014, 16, 4648-4661.

24. Rastogi, S.K.; Poulikakos. Second law optimization of forced convection of non-Newtonian fluids in ducts. J. Thermophys. Heat Trans. 1992, 6, 540-543.

25. Saouli, S.; Aiboud-Saouli, S. Entropy generation in channel flow for non-Newtonian Fluids with viscous dissipation effect. Res. J. Appl. Sci. 2007, 2, 900-907.

26. Jankowski, T.A. Minimizing entropy generation in internal flows by adjusting the shape of the cross-section. Int. J. Heat Mass Trans. 2009, 52, 3439-3445.

27. Shamshiri, M.; Khazaeli, R.; Ashrafizaadeh, M.; Mortazavi, S. Heat transfer and entropy generation analyses associated with mixed electrokinetically induced and pressure-driven power-law microflows. Energy 2012, 42, 157-169.

28. Escandon, J.; Bautista, O.; Mendez, F. Entropy generation in purely electroosmotic flows of non-Newtonian fluids in a microchannel. Energy 2013, 55, 486-496.

29. Lopez de Haro, M.; Cuevas, S.; Beltran, A. Heat transfer and entropy generation in the parallel plate flow of a power-law fluid with asymmetric convective cooling. Energy 2014, 66, 750-756.

30. Mahian, O.; Kianifar, A.; Kleinstreuer, C.; Al-Nimr, M.A.; Pop, I.; Sahin, A.Z. A review of entropy generation in nanofluid flow. Int. J. Heat Mass Trans. 2013, 65, 514-532.

31. Sahin, A.Z. Entropy generation in turbulent liquid flow through a smooth duct subjected to constant wall temperature. Int. J. Heat Mass Trans. 2000, 43, 1469-1478.

32. Moghaddami, M.; Mohammadzade, A.; Esfehani, E.A.V. Second law analysis of nanofluid flow. Energy Convers. Manag. 2011, 52, 1397-1405.

33. Singh, P.K.; Anoop, K.B.; Sundararajan, T.; Das, S.K. Entropy generation due to flow and heat transfer in nanofluids. Int. J. Heat Mass Trans. 2010, 53, 4757-4767.

34. Ellahi, R. The thermodynamics, stability, applications and techniques of differential type: A review. Rev.Theor. Sci. 2014, 2, 116-123.

35. Ellahi, R. The effects of MHD and temperature dependent viscosity on the flow of non-Newtonian nanofluid in a pipe: Analytical solutions. Appl. Math. Model. 2013, 37, 1451-1467. 
36. Zeeshan, A.; Ellahi, R. Series solutions for nonlinear partial differential equations with slip boundary conditions for non-Newtonian MHD fluid in porous space. Appl. Math. Inf. Sci. 2013, 7, 253-261.

37. Dodge, D.W.; Metzner, A.B. Turbulent flow of non-Newtonian systems. AIChE J. 1959, 5, 189-204.

38. Mishra, P.; Tripathi, G. Transition from laminar to turbulent flow of purely viscous non-Newtonian fluids in tubes. Chem. Eng. Sci. 1971, 26, 915-921.

(C) 2014 by the authors; licensee MDPI, Basel, Switzerland. This article is an open access article distributed under the terms and conditions of the Creative Commons Attribution license (http://creativecommons.org/licenses/by/4.0/). 